\title{
Synergistic apoptotic effect of celecoxib and luteolin on breast cancer cells
}

\author{
YE-WON JEON and YOUNG JIN SUH \\ Department of Surgery, The Catholic University of Korea St. Vincent's Hospital, Suwon, Republic of Korea
}

Received July 30, 2012; Accepted October 5, 2012

DOI: $10.3892 /$ or.2012.2158

\begin{abstract}
Breast cancer is heterogeneous and often hormonedependent. There are many breast cancer treatment options, including endocrine therapy, chemotherapy, radiotherapy and targeted therapy. Unfortunately, not all patients respond to first-line treatments, and others will eventually relapse despite an initial response. Therapeutic options for these patients are limited. In the past decade, several studies have demonstrated the antitumor effect of celecoxib and luteolin in breast cancer as single treatment. The effect of combination treatment of celecoxib and luteolin in human breast cancer cells has not been well characterized. The present study examined the synergistic effect of celecoxib and luteolin on the human breast cancer cell lines MCF-7 and MDA-MB-231. We analyzed cell proliferation, cell death, apoptosis and changes in protein expression by performing cell survival assays, apoptosis assays and western blotting. The combination treatment significantly decreased cancer cell viability, and it had a greater efficiency in killing tumor cells after $72 \mathrm{~h}$ of treatment, compared to treatment with either agent alone or the control in a concentration- and time-dependent manner $(\mathrm{P}=0.01)$. The combination treatment demonstrated a greater than additive increase in breast cancer cell apoptosis $(\mathrm{P}=0.01)$. Decreased levels of Akt phosphorylation (pAkt) were noted after celecoxib and luteolin combination treatment. The combination of celecoxib and luteolin provided superior inhibition of breast cancer cell growth than either celecoxib or luteolin treatment alone. These results suggest that celecoxib and luteolin combination may be a new possible treatment option for breast cancer.
\end{abstract}

\section{Introduction}

Breast cancer is a serious concern in many countries. Despite public education, cancer prevention and screening, increase in

Correspondence to: Professor Young-Jin Suh, Division of Breast and Thyroid Surgical Oncology, Department of Surgery, The Catholic University of Korea St. Vincent's Hospital, 93 Joongboo-Daero Paldal-gu, Suwon 442-723, Kyounggi-do, Republic of Korea

E-mail: yjsuh@catholic.ac.kr

Key words: breast cancer, MCF-7, MDA-MB-231, celecoxib, luteolin, apoptosis, Akt phosphorylation early diagnosis and advances in cancer management, 200,000 women develop breast cancer and more than 40,000 women die of breast cancer in the United States annually $(1,2)$. Since breast cancer is typically a hormone-dependent cancer, targeted endocrine therapy has led to a significant improvement in the outcomes for women with estrogen receptor (ER)-positive breast cancer. However, not all patients respond to first-line endocrine treatment, and other patients will eventually relapse despite an initial response to the treatment (3). Therapeutic options for these patients are limited. Additionally, patients with hormone receptor-negative breast tumors that are not human epidermal growth factor receptor 2 (HER2)-positive [(i.e., triple-negative breast cancer (TNBC)] account for $\sim 15 \%$ of breast cancer patients and these TNBC patients have not benefitted from generally well-tolerated, anti-HER2 drugs or targeted endocrine treatment strategies (4-6). Although considerable progress has been achieved through the development of new drugs and treatment strategies, current therapy is unable to elicit a clinical response in these patients (7).

In the last two decades, there have been major efforts to identify the signaling mechanisms responsible for these patients, and new therapeutic targets are being explored against cancer signaling pathways. Cyclooxygenase-2 (COX-2) is overexpressed in approximately $70 \%$ of in situ cases and $60 \%$ of invasive breast cancer, and elevated COX-2 expression in invasive breast cancer leads to increased tumor recurrence and decreased patient survival $(8,9)$. COX-2-specific inhibitors have been shown to promote growth arrest and induce apoptosis in various cancers, including breast cancer, by down-regulating the prosurvival signaling pathway, protein kinase B (PKB)/Akt $(10,11)$. The Western New York Exposures and Breast Cancer Study results showed a significant reduction in breast cancer risk associated with recent and adult lifetime non-steroidal anti-inflammatory drug use (odd ratio $0.73,95 \%$ confidence interval: 0.51-1.03) (12). Luteolin, 3', 4', 5, 7-tetrahydroxyflavone, is a common flavonoid that exists in many types of plants including fruits, vegetables, and medicinal herbs and acts as antioxidants, estrogenic regulators, and antimicrobial agents (13). Studies have been demonstrated that the anticancer property of luteolin is associated with inducing apoptosis, which involves redox regulation, DNA damage, protein kinase inhibition to cancel cell proliferation, and suppression of metastasis and angiogenesis $(13,14)$.

The objective of this study was to examine the effect of combination treatment of celecoxib and luteolin in human breast 
cancer cells and to subsequently determine the mechanism of action.

\section{Materials and methods}

Cell lines. Estrogen receptor-positive MCF-7 human breast cancer cells and estrogen receptor-negative MDA-MB-231 human breast cancer cells were obtained from the American Type Culture Collection (Manassas, VA, USA). The cells were cultured in RPMI-1640 medium (Sigma Chemical Co., St. Louis, MO, USA) supplemented with heat inactivated $10 \%$ fetal bovine serum with $300 \mathrm{mg} / \mathrm{l} \mathrm{L}$-glutamine, $25 \mathrm{mM}$ HEPES and $25 \mathrm{mM} \mathrm{NaHCO}, 100 \mu \mathrm{g} / \mathrm{ml}$ streptomycin, and $100 \mathrm{U} / \mathrm{ml}$ penicillin. The cells were grown in a humidified incubator at $37^{\circ} \mathrm{C}$ and $5 \% \mathrm{CO}_{2}$ atmosphere.

Cell survival assays. The effect of celecoxib (Celebrex ${ }^{\circledR}, \mathrm{Pfizer}$ Inc., St. Louis, MO, USA) and luteolin (Sigma Chemical Co.) on human breast cancer cell growth was determined by cell counting following XTT (Roche, Mannheim, Germany) assays. The XTT assay was performed as recommended by the manufacturer. One thousand cells were seeded in triplicates in 6-well plates with or without celecoxib and/or luteolin and assayed $72 \mathrm{~h}$ later. After incubation, cells treated with celecoxib were fixed in dimethyl sulfoxide (DMSO: Sigma Chemical Co.) and cells treated with luteolin were fixed in isopropyl Alcohol (Duksan pure chemicals, Kyungkido, Korea). Following fixation, the cells were treated with the XTT cell proliferation kit (Roche). The 570-nm absorbance was read using an automated spectrophotometric miniplate reader EL808 (Ultramicroplate reader; Bio-Tek Instruments, Inc., Winooski, VT, USA). The values were normalized and plotted as the percentage change compared to control cells (mean \pm standard error of the mean).

Apoptosis assays. Apoptotic MCF-7 and MDA-MB-231 cells were identified using the 5-bromo-2-deoxyuridine/terminal deoxynucleotidyl transferase (TdT)-mediated 2'-deoxyuridine 5'-triphosphate (dUTP)-biotin nick end labeling assay (TUNEL) and Annexin V-fluorescein isothiocyanate (FITC)/ propidium iodide (PI) staining. TUNEL assay (Apoptosis detection kit s7100; Chemicon international Inc, Temecula, USA) was performed according to the manufacturer's protocol. Briefly, total of $1 \times 10^{5}$ cells $/ \mathrm{ml}$ were incubated with celecoxib and/or luteolin for $72 \mathrm{~h}$. Then, the cells were washed and incubated with staining solution (10 $\mu \mathrm{l}$ of TdT reaction buffer, $0.75 \mu 1$ of TdT enzyme, and $8 \mu 1$ of FITC-dUTP) overnight. The following day, cells were rinsed and resuspended in $1 \mathrm{ml}$ $\mathrm{PI} / \mathrm{RNase}$ solution. After incubation in the dark for $30 \mathrm{~min}$ at room temperature, a manual cell count was performed to obtain the percentage of apoptotic cells.

Annexin V-FITC and PI staining was performed using the detection kit according to the manufacturer's protocol (BD Pharmingen, CA, USA). Total of $1 \times 10^{5}$ cells $/ \mathrm{ml}$ were incubated with celecoxib and/or luteolin for $72 \mathrm{~h}$. The cells were washed with cold phosphate-buffered saline and suspended in $100 \mathrm{ml}$ buffer (10 mM HEPES, $10 \mathrm{mM} \mathrm{NaOH}$ (pH 7.4), $140 \mathrm{mM} \mathrm{NaCl}$, $2.5 \mathrm{mM} \mathrm{CaCl}_{2}$ ). After $5 \mathrm{ml}$ of Annexin V-FITC and $5 \mathrm{ml}$ of PI were added, the cells were incubated for $15 \mathrm{~min}$ at room temperature in the dark. After this incubation, $400 \mathrm{ml}$ of binding buffer solution was added, and the cells were analyzed via flow cytometery. The quadrant containing Annexin V-FITCpositive/PI-negative cells represents early apoptotic cells, and the quadrant containing Annexin V-FITC-positive and PI-positive cells represents cells undergoing the end stage of apoptosis, necrotic cells or dead cells.

Western blotting. The cells were lysed, and the protein concentration was determined with the Bio-Rad colorimetric Assay (Bio-Rad Laboratories, Hercules, CA, USA). Lysates were resolved by western blot analysis on $10 \%$ sodium dodecylsulfate gels. The lanes were loaded with $50 \mu \mathrm{g}$ of protein and electrophoresed for $2 \mathrm{~h}$ at $90 \mathrm{~V}$. Proteins were transferred to nitrocellulose membranes. Membranes were blocked with 5\% nonfat dry milk and incubated with antibodies director against $\beta$-catenin (Santa Cruz Biotechnology, Santa Cruz, CA, USA), Akt (Cell Signaling, Beverly, MA, USA), STAT 3 (Cell Signaling) and pAkt (Cell Signaling) overnight at $4^{\circ} \mathrm{C}$. Membranes were washed and incubated with secondary antibody for $1 \mathrm{~h}$ at room temperature. Membranes were then developed, and protein signals were detected using enhanced chemiluminescence western blotting detection reagents (Amersham Biosciences, Buckinghamshire, UK). Membranes were incubated with antibody against $\beta$-actin (Santa Cruz Biotechnology) to assess equal protein loading, and results were subjected to densitometry analysis.

Statistical analysis. Statistical analyses were performed between control and treatment groups and among the different experimental groups. Continuous data are presented as the means and standard error deviations with median values. Comparisons of means were carried out using One way ANOVA. Differences with a value of $\mathrm{P}<0.05$ were considered to be statistically significant.

\section{Results}

Effect of celecoxib and luteolin on breast cancer cells in vitro. Breast cancer cells were treated with DMSO, isopropyl alcohol, celecoxib, luteolin, or a celecoxib + luteolin combination treatment. DMSO was used as a control for celecoxib and isopropyl alcohol was used as a control for luteolin. Cell viability was assessed using XTT assays. MCF-7 cells were treated with celecoxib and/or luteolin at various concentrations $(0,10$, 25, 50, 75, $100 \mu \mathrm{M}$ ). As shown in Fig. 1A based on the XTT assay results, the viability of the MCF-7 cells was inhibited by treatment with either celecoxib or luteolin after $72 \mathrm{~h}$ of treatment in a concentration-dependent manner (celecoxib: $\mathrm{P}=0.03$, luteolin: $\mathrm{P}=0.04)$. At a concentration of $50 \mu \mathrm{M}$, celecoxib decreased viability to $25.9 \%$ compared to controls, and $100 \mu \mathrm{M}$ celecoxib reduced viability to $73.8 \%$ compared to controls. At a concentration of $25 \mu \mathrm{M}$, luteolin decreased viability to $34.2 \%$ compared to controls, and at $50 \mu \mathrm{M}$ luteolin reduced viability to $76.3 \%$ compared to controls. MDA-MB-231 cells were treated with celecoxib and/or luteolin at various concentration $(0,10,25,50,75,100 \mu \mathrm{M})$. MDA-MB-231 cell viability was inhibited by $72 \mathrm{~h}$ of celecoxib treatment in a concentrationdependent manner (Fig. 1B, P=0.01). However, luteolin alone did not inhibit MDA-MB-231 cell viability $(\mathrm{P}=0.78)$. At a concentration of $50 \mu \mathrm{M}$, celecoxib decreased cell viability to $27.7 \%$ compared to controls, and at $100 \mu \mathrm{M}$, it reduced cell viability $81.6 \%$ compared to controls. At a concentration of 
A

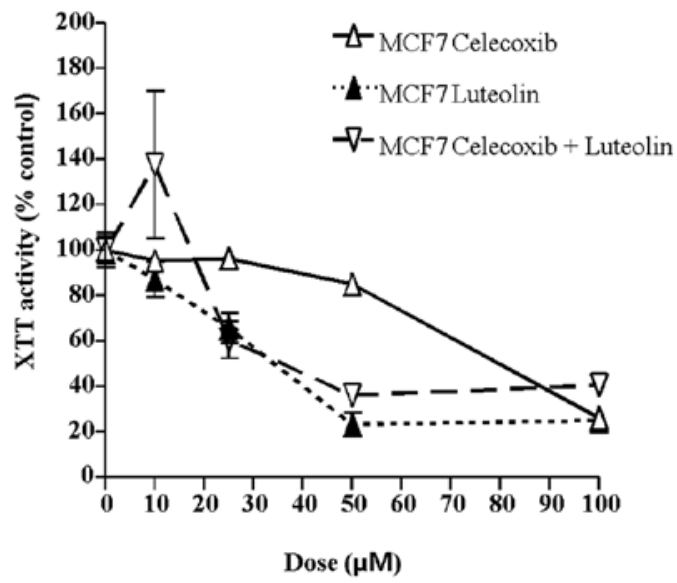

B

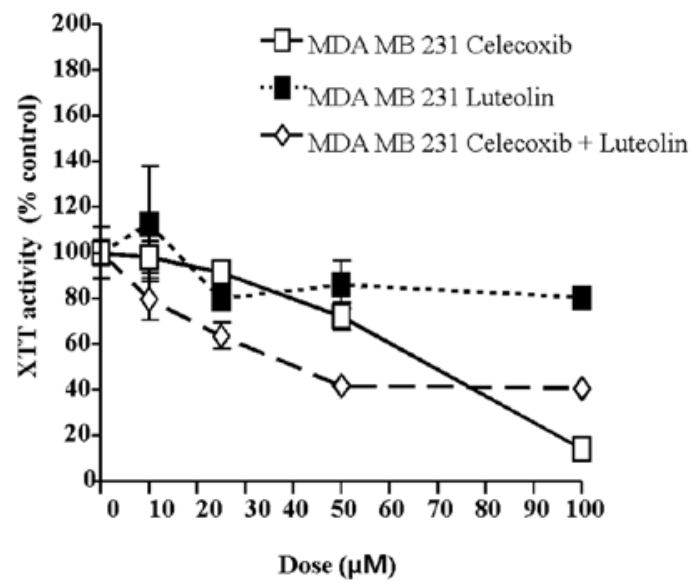

Figure 1. Cell viability of MCF-7 (A) and MDA-MB-231 (B) breast cancer cells. Cells were treated with celecoxib or luteolin or both as indicated for after $72 \mathrm{~h}$. Cell death was determined using the trypan blue exclusion method ( $\left.{ }^{*} \mathrm{P}<0.05\right)$.

A

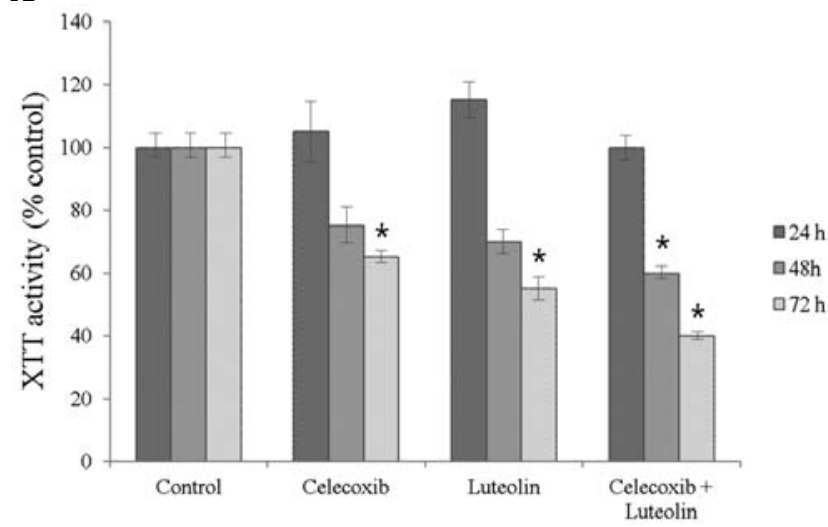

B

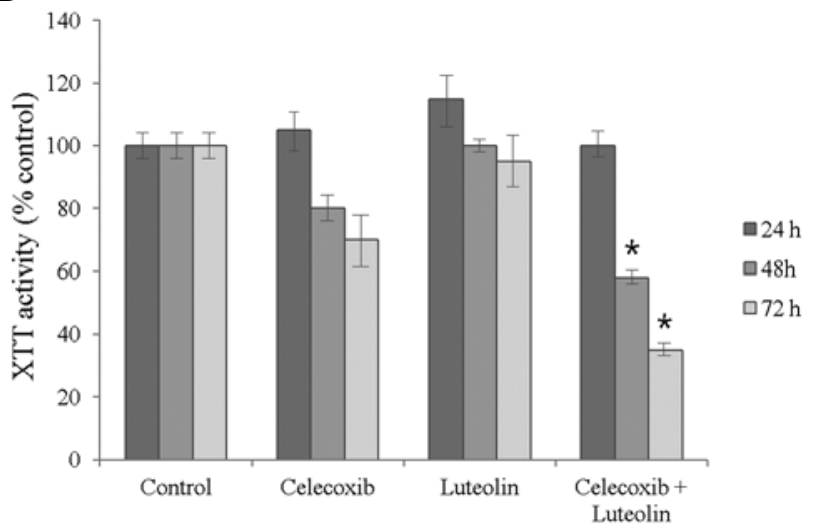

Figure 2. Cell viability of the breast cancer cell lines MCF-7 (A), MDA-MB-231 (B) treated with celecoxib (75 $\mu \mathrm{M})$ or luteolin (50 $\mu \mathrm{M})$ or both for 24,48 and $72 \mathrm{~h}$. Viability was determined using XTT assays ( $\mathrm{*}<0.05)$.

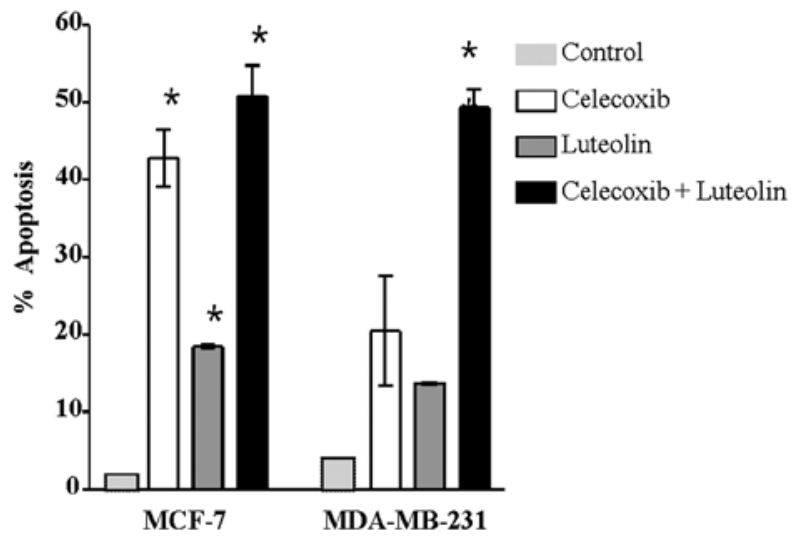

Figure 3. Apoptosis by celecoxib or luteolin or both in MCF-7 and MDA-MB231 breast cell lines shown by TUNEL assays. The cell lines were treated with celecoxib, luteolin, or the combination. Apoptotic cells were identified by brown staining. Quantification of the apoptotic cells was performed by manual counting $\left({ }^{*} \mathrm{P}<0.05,{ }^{* *} \mathrm{P}<0.01\right)$.

$25 \mu \mathrm{M}$, luteolin decreased cell viability to $20.0 \%$ compared to controls, and at $50 \mu \mathrm{M}$, it reduced cell viability to $20.8 \%$ compared to controls.
The XTT assays detected no differences in MCF-7 cell viability following treatment with either celecoxib $(75 \mu \mathrm{M})$ or luteolin $(50 \mu \mathrm{M})$ after $24 \mathrm{~h}$, but did show decreased viability after $48 \mathrm{~h}$ and $72 \mathrm{~h}$ (Fig. 2, P=0.04 and 0.02, respectively) MDA-MB-231 cell viability showed no differences following treatment for $24 \mathrm{~h}$, but celecoxib treatment resulted in a decrease in viability after $72 \mathrm{~h}$ of treatment, compared to $48 \mathrm{~h}$ $(\mathrm{P}=0.04)$. Luteolin treatment did not inhibit the viability of MDA-MB-231 cells time-dependently $(\mathrm{P}=0.13)$.

As shown in Figs. 1 and 2, the celecoxib and luteolin combination treatment significantly decreased cell viability and demonstrated greater efficiency in inducing tumor cell death after $72 \mathrm{~h}$ of treatment, compared to treatment with either alone or the controls in both cell lines $(\mathrm{P}=0.01)$. This was observed in a concentration- and time-dependent manner.

Analysis of apoptosis. The induction of apoptosis was evaluated using TUNEL assays and Annexin V- FITC/PI staining. The TUNEL assays demonstrated that the combination treatment resulted in significant increase in apoptosis induction compared with treatment with a single drug or controls (Fig. 3). In the MCF-7 cells, apoptosis was significantly different from 
Control
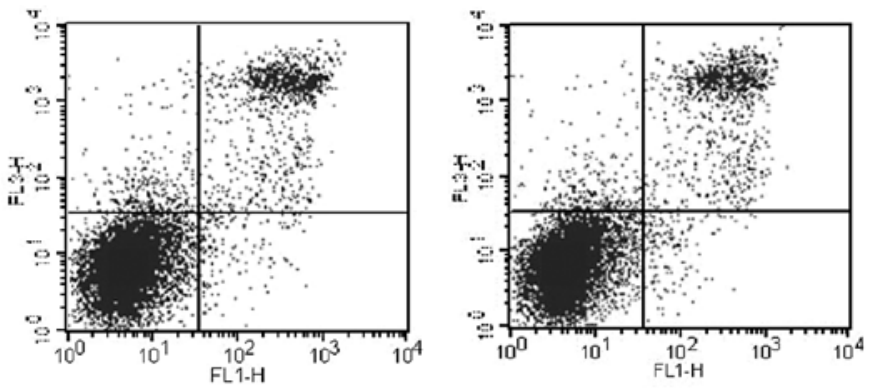

Celecoxib
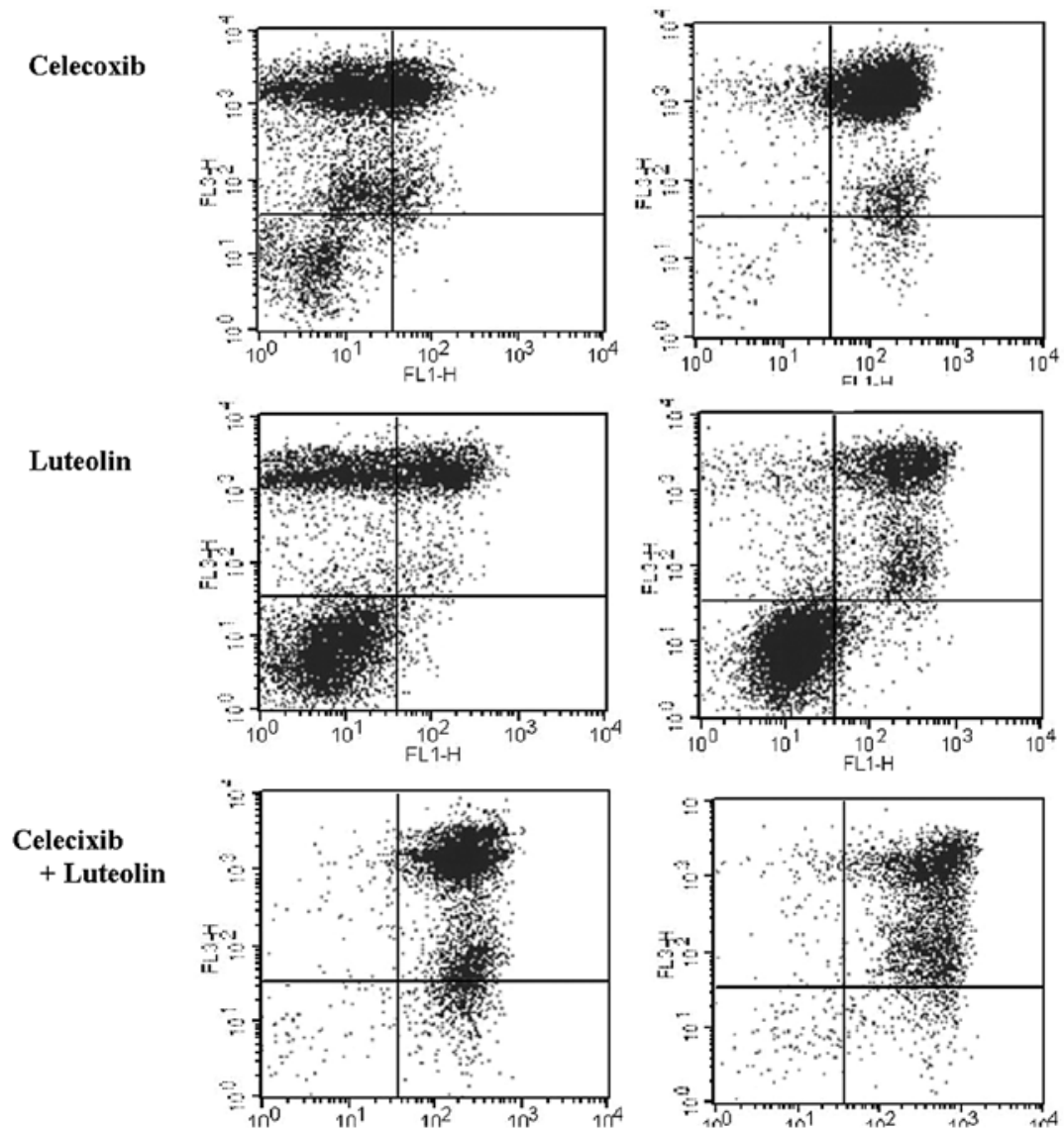

Figure 4. Apoptosis of MCF-7 (left) and MDA-MB-231 (right) breast cancer cell lines. Annexin V-FITC staining is represented on the horizontal axis and PI staining is represented on the vertical axis. The increase in the proportion of cells undergoing early and late apoptosis/necrosis was significantly higher after combination treatment in both cell lines than in the controls $(\mathrm{P}=0.01)$.

controls after combination treatment $(\mathrm{P}=0.03)$. Similarly, in the MDA-MB-231 cells, the induction of apoptosis was significantly higher after combination treatment compared to treatment with a single drug or controls $(\mathrm{P}<0.01)$. As shown in the Annexin V-FITC/PI staining (Fig. 4), the increase in the proportion of cells undergoing early and late apoptosis/ necrosis was significantly higher following celecoxib and luteolin combination treatment in both cell lines $(\mathrm{P}=0.01)$. The quantification of the Annexin V-FITC/PI staining is presented in Table I.

Celecoxib and luteolin combination decreases expression of $p A k t$. To determine the effect of celecoxib and/or luteolin treatment on the expression of representative pro-survival markers, western blots were performed to analyze the steady-state levels of $\beta$-catenin, STAT3, Akt and pAkt (Fig. 5). Decreased levels of Akt phosphorylation (pAkt) were noted after combination treatment compared with $\beta$-catenin, STAT3, and Akt $(\mathrm{P}<0.05)$.
pAkt was significantly decreased in the MCF-7 and MDA-MB231 cells following combination treatment $(\mathrm{P}=0.02)$.

\section{Discussion}

The effect of celecoxib and luteolin combination treatment for breast cancer has not been reported. However, in the present study, celecoxib and luteolin combination treatment of breast cancer cells resulted in a synergistic effect on the cell death in a concentration- and time-dependent manner when compared to treatment with either drug alone. Celecoxib was developed as a selective COX-2 inhibitor for the treatment of chronic pain in arthritis. However, considering the regulatory role of various antitumor signaling pathways, inhibition of COX-2 by celecoxib can induce proapoptotic effects. Suh et al reported that celecoxib significantly decreased MCF-7/HER2-18 and MDA-MB-436 breast tumor growth in vitro (15). Basu et al reported that celecoxib treatment altered the expression of 
Table I. Quantification of the analysis of Annexin V-FITC apoptosis.

\begin{tabular}{lccc}
\hline & $\begin{array}{c}\text { Lt. bottom } \\
\text { Quadrant viable cells }\end{array}$ & $\begin{array}{c}\text { Rt. bottom quadrant } \\
\text { Early apoptotic cells }\end{array}$ & $\begin{array}{c}\text { Rt. top quadrant } \\
\text { Late apoptotic cells }\end{array}$ \\
\hline MCF-7 & & & 20.51 \\
Control & 64.27 & 1.09 & 22.53 \\
Celecoxib & 13.75 & 0.69 & 21.52 \\
Luteolin & 50.23 & 1.15 & 87.56 \\
Celecoxib + Luteolin & 1.14 & 9.50 & 11.52 \\
MDA-MB-231 & & & 88.04 \\
Control & 83.56 & 1.33 & 31.11 \\
Celecoxib & 4.67 & 1.96 & 88.49 \\
Luteolin & 59.91 & 3.67 & \\
Celecoxib + Luteolin & 2.45 & 6.23 & \\
\hline
\end{tabular}
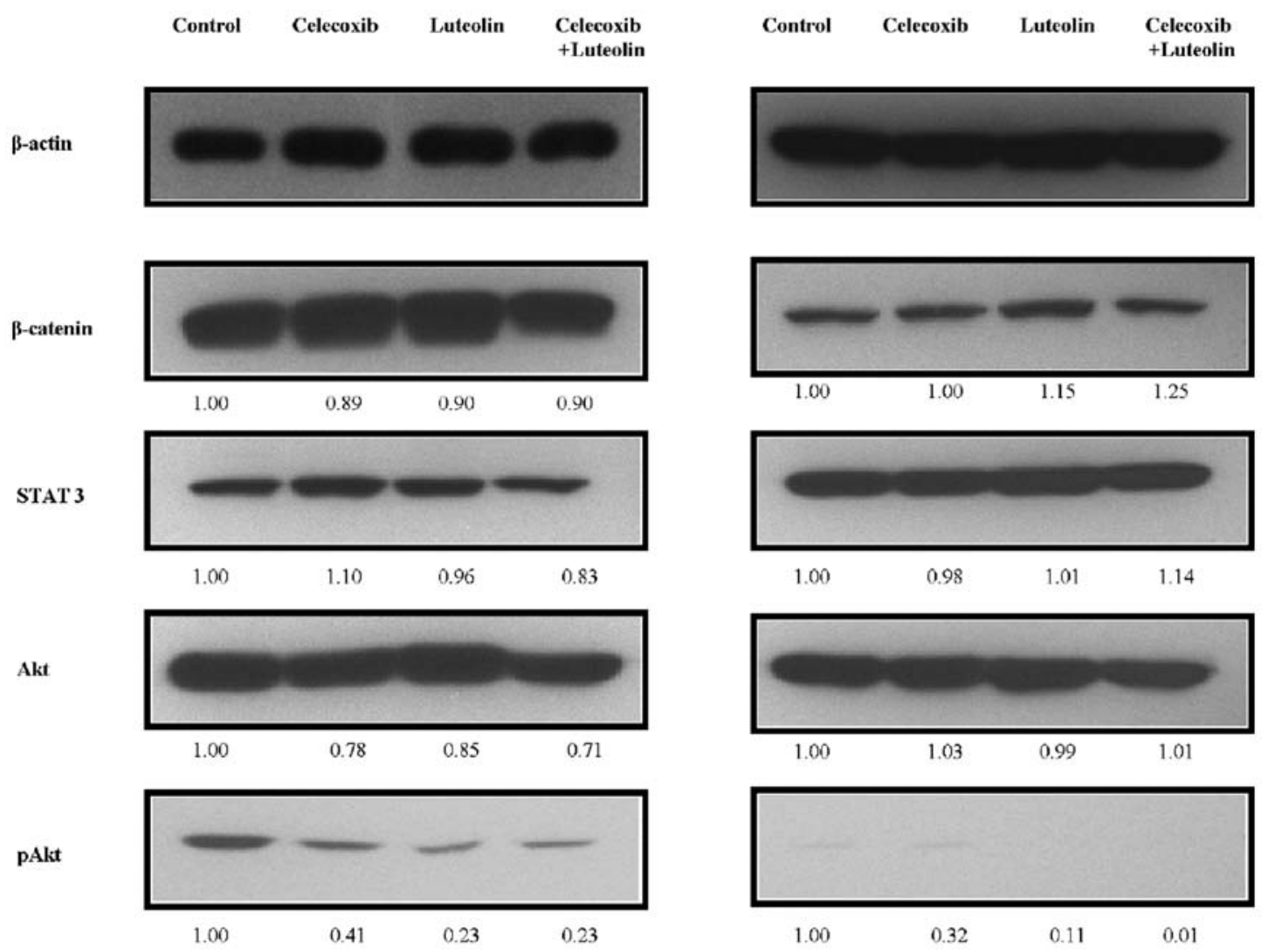

Figure 5. Western blot analysis of breast cancer cells treated with celecoxib, luteolin, or combination treatment. Both cell lines showed decreased expression of pAkt following the combination treatment when compared to controls. $\beta$-actin levels are shown to ensure equal protein loading.

genes associated with angiogenesis, proliferation, apoptosis, and the cell cycle (16). In vitro results were corroborated in vivo in tumor-bearing mice treated with celecoxib. In the present study, we have shown that celecoxib treatment decreases cell viability and increases cell death after $72 \mathrm{~h}$ of treatment in both ER-positive and -negative human breast cancer cells $(\mathrm{P}<0.05)$. Celecoxib inhibited tumor growth by increasing apoptosis. In the MCF-7 and MDA-MB-231 cell lines, the percentage of cells undergoing apoptosis increased by $45 \%$ and $26 \%$ from the control, respectively.
Luteolin induces several beneficial effects, including acting as an anti-inflammatory and anticancer agent. Chiang et al reported that luteolin significantly suppresses the growth of MCF-7 and MDA-MB-435 breast tumor in vitro (17). Shinh et al reported that luteolin significantly decreased MCF-7 and MDA-MB-231 breast tumor growth in vitro (18). We have shown that the viability of MCF-7 cells was inhibited by luteolin after $72 \mathrm{~h}$ of treatment in a time-dependent $(\mathrm{P}=0.02)$ and concentration-dependent manner $(\mathrm{P}=0.04)$. In the $\mathrm{MCF}-7$ cell line, the percentage of cells undergoing apoptosis increased 
by $20 \%$ from the control to the treated cells. However, in the MDA-MB-231 cell line, luteolin treatment did not inhibit cell viability concentration-dependently $(\mathrm{P}=0.78)$ or timedependently $(\mathrm{P}=0.13)$.

In the MCF-7 and MDA-MB-231 cells, the celecoxib and luteolin combination treatment significantly decreased cell viability and was more efficient in killing tumor cells after $72 \mathrm{~h}$ of treatment, compared to treatment with only one drug or the control $(\mathrm{P}=0.01)$. The percentage of cells undergoing apoptosis increased by 52 and $50 \%$ from the control in the MCF-7 and MDA-MB-231 cells, respectively. The antitumor effect of the celecoxib and luteolin combination treatment was more significant in the MDA-MB-231 cells compared to treatment with either drug alone (celecoxib: $20 \%$ and luteolin: no effect, and this effect was more significant than in the MCF-7 cells $(\mathrm{P}<0.05$ vs. $\mathrm{P}<0.01)$.

The pro-oncogenic mechanism of the COX-2 is not fully understood. Ghosh et al showed that prostaglandin $\mathrm{E}_{2}\left(\mathrm{PGE}_{2}\right)$ was the major downstream effector of COX-2 (19). Activation of the epidermal growth factor receptor (EGFR) via $\mathrm{PGE}_{2}$ could result in activation of Ras and the mitogen-activated protein kinase (MAPK) pathway $(20,21)$. Protein kinase B (Akt/PKB) activity is implicated in K-Ras-induced expression of COX-2, and the stabilization of COX-2 mRNA partly depends upon the activation of Akt/PKB (22). For example, $\mathrm{PGE}_{2}$ inhibits apoptosis by stimulating the PI3kinase/Akt pathway. Furthermore, celecoxib was able to bind to and inhibit 3-phosphoinositide-dependent protein kinase-1 (PDK1). PDK1 is an essential component of cell growth and survival signaling pathways involving PI3K, upstream of PDK1, and Akt/PKB, downstream of PDK1 $(11,23)$. Since Akt/PKB has a regulatory role of in pro-oncogenic pathways, the discovery of its inhibition by celecoxib provides a suitable explanation for the drug's COX-2 anticancer effects.

As an anticancer agent, luteolin inhibits proliferation of SCC-9 human oral squamous carcinoma cells, blocks DMBAinduced DNA adduct formation and cytotoxicity in MCF-7 cells, and inhibits CYP1A1 and CYP1B1 EROD activity (24-26). Furthermore, luteolin inhibits the proliferation of several cancer cell line via the inhibition of the protein tyrosine kinase activity and autophosphorylation of EGFR, transphosphorylation of the EGFR downstream effecter protein enolase and activation of MAPK/ERK (27). Luteolin is able to inhibit IGF-1-induced activation of IGF-1R and Akt, and phosphorylation of Akt (28).

To determine whether celecoxib and luteolin alter prosurvial signaling in breast cancer cells, we used western blotting to examine Akt phosphorylation. Decreased levels of pAkt were noted after treatment with either drug $(\mathrm{P}<0.05)$. Akt phosphorylation was further reduced by combination treatment in the MCF-7 and MDA-MB-231 cells $(\mathrm{P}=0.02)$. We demonstrated that enhanced antitumor activity by celecoxib and luteolin combination treatment could result in decreased levels of Akt phosphorylation.

Therapeutic selectivity is important in anticancer treatments. The use of celecoxib has drawn much attention since the review of cardiac safety compared to another COX-2 inhibitor (29). Horinaka et al and Chen et al showed that luteolin induces marginal cytotoxicity in normal cells $(30,31)$. These results imply that luteolin is relatively safe when used as an anticancer agent. The anticancer properties of luteolin have been tested in conjunction with other anticancer drugs. Luteolin was observed to increase drug-induced cytotoxicity in a variety of cancer cells (14). These results support the idea that a celecoxib and luteolin combination treatment will provide a better therapeutic strategy to treat breast cancer than treatment with celecoxib alone.

Our study has several limitations. This study examines breast cancer cell lines in vitro. Additional studies are required to demonstrate the efficacy of celecoxib and luteolin combination treatment in vivo. Even though, the effect of celecoxib and luteolin combination treatment was demonstrated in both ER-positive and -negative human breast cancer cells, breast cancer is a heterogeneous disease, therefore HER2 receptor expression is important for determining definite breast cancer treatment. This can be answered quite soon with our collateral studies. In spite of these limitations, our study demonstrated that a celecoxib and luteolin combination treatment is effective in killing breast cancer cells. To our knowledge, this is first study of a celecoxib and luteolin combination treatment in breast cancer.

In conclusion, we demonstrated that a combination of celecoxib and luteolin could provide superior inhibition of breast cancer cell growth than either celecoxib or luteolin treatment alone. Additional studies, in human breast cancer cells that overexpress HER 2 and in vivo xenograft models, are needed to demonstrate the effect of celecoxib and luteolin combination in human breast cancer. These results suggest that celecoxib and luteolin combination treatment might be a new treatment modality that could improve prevention of breast cancer and decrease recurrence after early breast cancer treatment. Celecoxib and luteolin in combination with other anticancer drugs may improve the therapeutic value of the combined agents by allowing the use of lower, sub-toxic doses to achieve a more effective cancer treatment.

\section{Acknowledgements}

The study was funded by Catholic University of Korea St. Vincent's Hospital.

\section{References}

1. Glass AG, Carreon JD, Lacey JV Jr and Hoover RN: Breast cancer incidence, 1980-2006: combined roles of menopausal hormone therapy, screening mammography, and estrogen receptor status. J Natl Cancer Inst 99: 1152-1161, 2007.

2. Jemal A, Siegel R, Ward E, Hao Y, Xu J and Thun MJ: Cancer statistics, 2009. CA Cancer J Clin 59: 225-249, 2009.

3. Ring A and Dowsett M: Mechanisms of tamoxifen resistance. Endocr Relat Cancer 11: 643-658, 2004.

4. Konecny G, Pauletti G, Pegram M, et al: Quantitative association between HER-2/neu and steroid hormone receptors in hormone receptor-positive primary breast cancer. J Natl Cancer Inst 95: 142-153, 2003.

5. Slamon DJ, Godolphin W, Jones LA, et al: Studies of the HER-2/ neu proto-oncogene in human breast and ovarian cancer. Science 244: 707-712, 1989.

6. Nielsen TO, Hsu FD, Jensen K, et al: Immunohistochemical and clinical characterization of the basal-like subtype of invasive breast carcinoma. Clin Cancer Res 10: 5367-5374, 2004.

7. Peto R, Boreham J, Clarke M, Davies C and Beral V: UK and USA breast cancer deaths down 25\% in year 2000 at ages 20-69 years. Lancet 355: 1822, 2000.

8. Boland GP, Butt IS, Prasad R, Knox WF and Bundred NJ: COX-2 expression is associated with an aggressive phenotype in ductal carcinoma in situ. Br J Cancer 90: 423-429, 2004. 
9. Crawford YG, Gauthier ML, Joubel A, Mantei K, Kozakiewicz K, Afshari CA and Tlsty TD: Histologically normal human mammary epithelia with silenced p16(INK4a) overexpress COX-2, promoting a premalignant program. Cancer Cell 5: 263-273, 2004

10. Basu GD, Pathangey LB, Tinder TL, Lagioia M, Gendler SJ and Mukherjee P: Cyclooxygenase-2 inhibitor induces apoptosis in breast cancer cells in an in vivo model of spontaneous metastatic breast cancer. Mol Cancer Res 2: 632-642, 2004.

11. Kulp SK, Yang YT, Hung CC, et al: 3-phosphoinositide-dependent protein kinase-1/Akt signaling represents a major cyclooxygenase2 -independent target for celecoxib in prostate cancer cells. Cancer Res 64: 1444-1451, 2004.

12. Brasky TM, Bonner MR, Moysich KB, et al: Non-steroidal antiinflammatory drug (NSAID) use and breast cancer risk in the Western New York Exposures and Breast Cancer (WEB) Study. Cancer Causes Control 21: 1503-1512, 2010.

13. Birt DF, Hendrich S and Wang W: Dietary agents in cancer prevention: flavonoids and isoflavonoids. Pharmacol Ther 90: 157-177, 2001.

14. Lin Y, Shen HM, Shi R and Wang X: Luteolin, a flavonoid with potential for cancer prevention and therapy. Curr Cancer Drug Targets 8: 634-646, 2008 .

15. Suh YJ, Chada S, McKenzie T, Liu Y, Swisher SG, Lucci A and Hunt KK: Synergistic tumoricidal effect between celecoxib and adenoviral-mediated delivery of mda-7 in human breast cancer cells. Surgery 138: 422-430, 2005.

16. Basu GD, Liang WS, Stephan DA, Wegener LT, Conley CR, Pockaj BA and Mukherjee P: A novel role for cyclooxygenase-2 in regulating vascular channel formation by human breast cancer cells. Breast Cancer Res 8: R69, 2006.

17. Chiang CT, Way TD and Lin JK: Sensitizing HER2-overexpressing cancer cells to luteolin-induced apoptosis through suppressing p21(WAF1/CIP1) expression with rapamycin. Mol Cancer Ther 6 : 2127-2138, 2007

18. Shih YL, Liu HC, Chen CS, et al: Combination treatment with luteolin and quercetin enhances antiproliferative effects in nicotine-treated MDA-MB-231 cells by down-regulating nicotinic acetylcholine receptors. J Agric Food Chem 58: 235-241, 2010

19. Ghosh N, Chaki R, Mandal V and Mandal SC: COX-2 as a target for cancer chemotherapy. Pharmacol Rep 62: 233-244, 2010.

20. Sheng H, Shao J, Dixon DA, Williams CS, Prescott SM, DuBois RN and Beauchamp RD: Transforming growth factor betal enhances Ha-ras-induced expression of cyclooxygenase-2 in intestinal epithelial cells via stabilization of mRNA. J Biol Chem 275: 6628-6635, 2000
21. Sheng H, Williams CS, Shao J, Liang P, DuBois RN and Beauchamp RD: Induction of cyclooxygenase-2 by activated Ha-ras oncogene in Rat-1 fibroblasts and the role of mitogenactivated protein kinase pathway. J Biol Chem 273: 22120-22127, 1998.

22. Sheng H, Shao J and Dubois RN: K-Ras-mediated increase in cyclooxygenase 2 mRNA stability involves activation of the protein kinase B1. Cancer Res 61: 2670-2675, 2001.

23. Arico S, Pattingre S, Bauvy C, Gane P, Barbat A, Codogno P and Ogier-Denis E: Celecoxib induces apoptosis by inhibiting 3 -phosphoinositide-dependent protein kinase-1 activity in the human colon cancer HT-29 cell line. J Biol Chem 277: 27613-27621, 2002.

24. Browning AM, Walle UK and Walle T: Flavonoid glycosides inhibit oral cancer cell proliferation - role of cellular uptake and hydrolysis to the aglycones. J Pharm Pharmacol 57: 1037-1042, 2005.

25. Ciolino HP, Wang TT and Yeh GC: Diosmin and diosmetin are agonists of the aryl hydrocarbon receptor that differentially affect cytochrome P450 1A1 activity. Cancer Res 58: 2754-2760, 1998.

26. Doostdar H, Burke MD and Mayer RT: Bioflavonoids: selective substrates and inhibitors for cytochrome P450 CYP1A and CYP1B1. Toxicology 144: 31-38, 2000.

27. Lee LT, Huang YT, Hwang JJ, et al: Blockade of the epidermal growth factor receptor tyrosine kinase activity by quercetin and luteolin leads to growth inhibition and apoptosis of pancreatic tumor cells. Anticancer Res 22: 1615-1627, 2002.

28. Fang J, Zhou Q, Shi XL and Jiang BH: Luteolin inhibits insulinlike growth factor 1 receptor signaling in prostate cancer cells. Carcinogenesis 28: 713-723, 2007.

29. Solomon SD, McMurray JJ, Pfeffer MA, et al: Cardiovascular risk associated with Celecoxib in a clinical trial for Colorectal Adenoma Prevention. N Eng J Med 352: 1071-1080, 2005.

30. Horinaka M, Yoshida T, Shiraishi T, et al: Luteolin induces apoptosis via death receptor 5 upregulation in human malignant tumor cells. Oncogene 24: 7180-7189, 2005.

31. Chen D, Chen MS, Cui QC, Yang H and Dou QP: Structureproteasome-inhibitory activity relationships of dietary flavonoids in human cancer cells. Front Biosci 12: 1935-1945, 2007. 